The role of multi-disciplinary team work was a key factor in this practice development project.

\section{CORE COMPETENCIES IN OCCUPATIONAL MEDICINE IN BRAZILIAN PROCESSES FOR SPECIALIST EDUCATION, CONTINUOUS EDUCATION AND CERTIFICATION}

\begin{abstract}
${ }^{1}$ Elizabeth Costa Dias*, ${ }^{2}$ Raquel Bonesana de Oliveira, ${ }^{3}$ Danielle NPDella Torre, ${ }^{4}$ Claudia Vasques Chiavegatto. ${ }^{1}$ Professor Federal University of Minas Gerais, Scientific Director Brazilian National Association of Occupational Medicine; ${ }^{2}$ Occupational Physician Director Continuous Education Brazilian National Association of Occupational Medicine; ${ }^{3}$ Medical Resident in Occupational Medicine, Clinical Hospital UFMG; ${ }^{4}$ Occupational physician, Professor and Consultant
\end{abstract}

\subsection{6/oemed-2018-ICOHabstracts.310}

Introduction The core competencies required for occupational physicians (OP) need to be adapted continuously evolving around the world. Since 2002 the Brazilian National Association of Occupational Medicine (ANAMT) is guiding the training and certification processes, quite similar to other Occupational Health Associations in the European Union or in some other individual countries around the world. The aim of this study was to describe the process and the results of a Brazilian assessment, to actualize existing data, seek consensus and identify the common core competencies required for OP nowadays.

Methods A modified Delphi study was carried out among 223 OP's, associate members of the ANAMT.The study was conducted in two rounds (round 1: rating of the principal competency domains; round 2: ranking) using a questionnaire based on the specialist training syllabus of different countries, expert panel reviews and conference discussions.

Result There was broad consensus on all identified competency domains with scores of $90 \%$ and over in every domain. In the first step the results were organised in six domains, 24 general competencies and 124 specific competencies. The competency to act ethically and professionally was considered as core around which the four basic domains are organised: analysis and intervention on the health condition; study of working conditions and proposals for improvement; integrated health management; safety, environmental and health promotion and education. The sixths domain, considered as transversal to the others, includes skills in communication, interpersonal relations, teamwork and leadership as well as knowledge management. In the second round of the study, this competency cast was reorganised and hierarchized, resulting in 4 main domains and 60 specific competencies.

Discussion and conclusions This study has established the current priorities amongst Brazilian OP's concerning the core competencies required for $\mathrm{OH}$ practice and the results seem in concordance with similar studies conducted worldwide. These findings can serve as a platform for the qualification processes for medical residence/specialisation trainings and specialist certification.

\section{INDUSTRIAL WELFARE NURSE COURSES IN HUNGARY BETWEEN 1933 AND 1945}

${ }^{1,2} \mathrm{HE}$ Hirdi*. ${ }^{1}$ Federation of Occupational Health Nurses within the EU, EU; ${ }^{2}$ Chamber of Hungarian Healthcare Professionals, Hungary

10.1136/oemed-2018-ICOHabstracts.311
Introduction Occupational Health Nursing aims at securing the health, safety and well-being of the workforce. The purpose of this presentation is to introduce the origin of specific education for the occupational health nurses, which fell into oblivion by this time.

Methods The research method was a holistic data gathering in which printed and online available archival, literature, legal sources and press-material between 1883 and 1950 were explored. A search of the electronic databases was concluded, using the keywords 'nursing', 'history', 'education' and 'teaching'. Content analysis using bibliometric and historical research methods on available documentation sources.

Results The idea of the training of Industrial Welfare Nurses developed by Dr Mária Baloghy (1895-1970?) secondary school teacher. The first factory-nurse course has been started in 1933 in Budapest, Hungary. Participants of the course had to suit strict admission requirements. The two-years full-time (45 hours/week) training covered four major fields: health, social, legal and cultural studies. The Minister of Industry supported the development of the institutional system of factory nurses from 1935. There are data available with reference to the uninterrupted existence of training until 1945; according to these more than 150 women obtained a qualification. Requirements of taking up an $\mathrm{OH}$ nurse job were regulated by law from 1941 .

Conclusion It has been stated that $\mathrm{OH}$ nurse education has an 85 -year-old history in Europe that throw new light upon theories until now about origin of $\mathrm{OH}$ nursing education.

\section{Emergency Preparedness and Response in Occupational Health}

\section{EMERGENCY PREPAREDNESS AMONG THE FARM WORKERS WHILE PERFORMING THE FARM ACTIVITIES DURING SUMMER MONTHS}

${ }^{1} \mathrm{~K}$ Kesarwani*, ${ }^{2} \mathrm{P}$ Sharma. 'Ph.D. Scholar, G.B. Pant University of Agriculture and Technology, Pantnagar, India; ${ }^{2}$ Professor, G.B. Pant University of Agriculture and Technology, Pantnagar, India

\subsection{6/oemed-2018-ICOHabstracts.312}

Introduction India being mainly an agricultural country, economy and further its growth purely depends on farming, making agriculture as most preferred occupation nationwide. The exposure of farm workers to this extreme weather condition especially during the summer months (March-June) is just hampering their health. Worsening of health is more prominent because most of farm activities are carried out manually under direct heat exposure and lack of awareness among the farm workers regarding the health hazards and even the unavailability of the protective methods. The combination of manual farm activities and heat exposure is a health, environmental and occupational issue, which need serious concern. The study focused on finding out the adaptive methods adopted by the farm workers.

Methods The study was undertaken to find out the adaptive methods adopted by the farm workers while accomplishing the farm activities during month of March to June and develop PPE to protect them from heat stress.

Results It was revealed that 98.9 percent of the farmers increased daily water intake, whereas, 27.8 percent increased liquid diet in their daily food intake. Regular intake of the 